\title{
Application of biocomposite edible coatings based on pea starch and guar gum on quality, storability and shelf life of 'Valencia' oranges
}

Bahareh Saberi, John B. Golding, José R. Marques, Penta Pristijono, Suwimol Chockchaisawasdee, Christopher J. Scarlett and Costas E. Stathopoulos

This is the accepted manuscript (C) 2017, Elsevier Licensed under the Creative Commons AttributionNonCommercial-NoDerivatives 4.0 International: http://creativecommons.org/licenses/by-nc-nd/4.0/

\section{(cc) $\mathrm{BY}-\mathrm{NC}-\mathrm{ND}$}

The published article is available from doi: https://doi.org/10.1016/j.postharvbio.2017.11.003 
1 Application of biocomposite edible coatings based on pea starch and guar gum on quality,

2 storability and shelf life of 'Valencia' oranges

3 Bahareh Saberi ${ }^{a^{*}}$, John B. Goldinga, ${ }^{\mathrm{a}, \mathrm{b}}$, José R. Marques ${ }^{\mathrm{b}}$, Penta Pristijono ${ }^{\mathrm{a}}$, Suwimol

4 Chockchaisawasdee $^{\mathrm{a}, \mathrm{c}}$, , Christopher J. Scarlett ${ }^{\mathrm{a}}$ and Costas E. Stathopoulos ${ }^{\mathrm{c}}$

5

6 a School of Environmental and Life Sciences, University of Newcastle, Ourimbah, NSW 2258,

7 Australia

$8 \quad$ b NSW Department of Primary Industries, Ourimbah, NSW 2258, Australia

$9{ }^{\mathrm{c}}$ Division of Food and Drink, School of Science, Engineering and Technology, University of 10 Abertay, Dundee DD1 1HG, UK

11

$12 *$ Correspondence to:

13 Bahareh Saberi

14 School of Environmental and Life Sciences, Faculty of Science and Information Technology, 15 University of Newcastle, Brush Road, Ourimbah, NSW 2258, Australia.

16 Tel: +61 449968763; Fax: +61 24348 4145; E-mail: bahareh.saberi@uon.edu.au

17

18 
Novel edible composite coatings based on pea starch and guar gum (PSGG), PSGG blended with lipid mixture containing the hydrophobic compounds shellac and oleic acid (PSGG-Sh), and a layer-by-layer (LBL) approach (PSGG as an internal layer and shellac as an external layer), were investigated and compared with a commercial wax (CW) and uncoated fruit on postharvest quality of 'Valencia' oranges held for up to four weeks at $20{ }^{\circ} \mathrm{C}$ and $5{ }^{\circ} \mathrm{C}$ with an additional storage for $7 \mathrm{~d}$ at $20{ }^{\circ} \mathrm{C}$. The incorporation of lipid compounds into the PSGG coatings (PSGG-Sh) generally resulted in the best performance in reducing fruit respiration rate, ethylene production, weight and firmness loss, peel pitting, and fruit decay rate of the coated oranges. Fruit coated with PSGG-Sh and a single layer PSGG coatings generally resulted in higher scores for overall flavor and freshness after four weeks at $5{ }^{\circ} \mathrm{C}$ followed by one week at $20{ }^{\circ} \mathrm{C}$ than uncoated fruit, as assessed by a sensory panel. Although the LBL coating reduced weight loss and respiration rate with improved firmness retention to a greater extent than the single layer PSGG coating, the bilayer coating also resulted in higher levels of ethanol causing increased perception of off-flavors. Overall results suggested that PSGG-based edible coatings could be a beneficial substitute to common commercial waxes for maintaining quality and storability, as well as extending shelf life of citrus fruit and potentially other fresh horticultural produce.

Keywords: Biocomposite edible coating, Citrus, Pea starch, Guar gum, Postharvest quality 


\section{Introduction}

41 Edible films and coatings are widely used to maintain the quality and shelf life of many horticultural products, including citrus (Baldwin et al., 2011). Edible films and coatings act as semi-permeable membranes which restrict the movement of gases and water vapor to reduce the rate of respiration and water loss from the fruit. Many films/coatings due to their barrier and mechanical properties can reduce the rate of physiological postharvest degradation (Baldwin, 1994; Baldwin et al., 1995; Park, 1999).

In many countries, harvested citrus fruit are commonly waxed during their processing and packing. This is to replace the natural wax which is damaged/removed with commercial harvesting, handling, processing and packing (Valencia- Chamorro et al., 2010). The commercial application of waxes not only reduces weight loss and shrinkage, but also enhances shine by increasing gloss (Rojas-Argudo et al., 2009). However, some waxes have been shown to negatively alter the internal atmosphere of the fruit by inducing anaerobic off-flavor development with the restriction of respiratory gas exchange (Martínez-Jávega et al., 1989).

Many modern citrus waxes are made of shellac (derived from the lac bug, Kerria lacca) or carnauba (derived from the leaves of the carnauba palm, Copernicia prunifera). However there is a need to improve the efficiency and sustainability of waxes applied to citrus.

Readily sourced and inexpensive coating materials which are effective at maintaining fruit quality during storage and shelf life are required. Pea (Pisum sativum) is widely grown around the world and contains $22-45 \%$ starch as the most plentiful carbohydrate in the seed (Hoover and Sosulski, 1991). Pea starch (PS) is comprised of a mixture of two homopolymers; a linear fraction, amylose, and a highly branched fraction, amylopectin. They are made of units of Dglucose with only two types of chain linkages, an $\alpha-(1 \rightarrow 4)$ of the main chain and an $\alpha-(1 \rightarrow 6)$ of the branch chains (Liu, 2005). Pea starch has high content of amylose; therefore it is a 
potential option for the production of starch-based edible films (Van Soest et al., 2002). Guar gum $(\mathrm{GG})$, which is derived from the endosperm of the guar bean (Cyamopsis tetragonoloba), is a type of linear galactomannan with ratio of mannose to galactose units of 2:1 (Prajapat and Gogate, 2015). The molecular structure of guar gum is composed of $\beta(1 \rightarrow 4)$-linked mannopyranose backbone, with several branch points from the C-6 position of mannopyranose, linked by $\alpha(1 \rightarrow 6)$ bond to a single D-galactopyranose sugar (Whistler and BeMiller, 1993). Owing to the long polymeric chain, high molecular weight and wide availability of pea starch and guar gum, they can be potential alternatives for production of renewable source based biodegradable edible coatings or packaging materials. In our previous studies, it has been shown that pea starch in combination with guar gum can form biocomposite edible films with preferable physical, optical and mechanical properties (Saberi et al., 2016a; Saberi et al., 2016b; Saberi et al., 2016c). However, edible coatings based on pea starch and guar gum have not been comprehensively explored as fruit coatings.

Due to the hydrophilic nature of pea starch-guar gum (PSGG) film, it is necessary to add a hydrophobic substance for decreasing the water sensitivity of the film. In this experiment, shellac (Sh) was added as a resin-based hydrophobic substance to increase its capability in increasing gloss and decrease water loss (Arnon et al., 2015). However, an issue with shellac films is their lack of permeability to gases, which results in the accumulation of ethanol and carbon dioxide $\left(\mathrm{CO}_{2}\right)$ and the development of off-flavors during storage (Baldwin et al., 1995; Dhall, 2013; Porat et al., 2005).

In this study, we investigated the influence of pea starch-guar gum (PSGG), pea starch-guar gum-shellac (PSGG-Sh), and PSGG/Sh bilayer composite coating, formed by first applying PSGG and then shellac (Sh) compared with fruit coated with commercial wax and uncoated fruit (control) on maintaining the quality of fresh 'Valencia' oranges during four weeks at 20 
${ }^{\circ} \mathrm{C}$ and four weeks of storage at $5^{\circ} \mathrm{C}$ followed by one week at $20^{\circ} \mathrm{C}$, simulating marketing shelf life.

\section{Materials and methods}

91

\subsection{Materials}

92 Canadian non-GMO (non-genetically modified organism) yellow pea starch with $13.2 \%$ 93 moisture, $0.2 \%$ protein, $0.5 \%$ fat, $0.3 \%$ ash, and $36.25 \pm 0.32 \%$ amylose was used in all experiments (supplied by Yantai Shuangta Food Co., Jinling Town, China). Guar gum (E-412) was purchased from The Melbourne Food Ingredient Depot, Brunswick East, Melbourne, Australia. Food grade alcohol-based solution of shellac and Citrus Gleam (a shellac-based commercial wax) were purchased from Castle Chemicals (castlechem.com.au), NSW, Australia. Oleic acid (OA) and Tween-20 were obtained from Sigma Aldrich, Australia. Glycerol was from Ajax Finechem Pty. Ltd, Australia and used as a plasticizer. All other chemicals were purchased from Merck Millipore, Pty., VIC, Melbourne, Australia.

\subsection{Sample preparation}

'Valencia' oranges (Citrus sinensis L. Osbeck) were obtained from a local commercial citrus grower (Griffith, NSW, Australia) at commercial maturity and transported to the NSW Department of Primary Industries (Ourimbah, NSW, Australia). Oranges were selected based on homogeneity in shape, color, size, firmness and free of mechanical wounds or fungal decay.

Selected oranges were dipped in a solution of $1150 \mu \mathrm{L} \mathrm{L}^{-1}$ fludioxonil (Scholar ${ }^{\circledR}$, Syngenta Australia) for one min, then drained and air-dried at $20^{\circ} \mathrm{C}$ before coating application.

\subsection{Coating formulations}

\subsubsection{PSGG coatings}


110 Pea starch $(2.5 \mathrm{~g})$, guar gum $(0.3 \mathrm{~g})$ and $25 \% \mathrm{w} / \mathrm{w}$ glycerol as plasticizer based on the dry film matter were dissolved in $100 \mathrm{~mL}$ degassed deionized water. The solution was heated at $90{ }^{\circ} \mathrm{C}$ for 20 min upon constant stirring. The suspension was then cooled until room temperature with mild magnetic stirring (Saberi et al., 2016b). The film solution was prepared one day before use.

\subsubsection{PSGG-Sh coatings}

The PSGG-Sh composite mixture was prepared by adding oleic acid ( $1 \%$ of dry weight of pea starch and guar gum) as emulsifier and Tween-20 (0.3 mL) as surfactant to the PSGG solution made as described above. Food grade alcohol-based solution of shellac at $40 \%$ (dry weight of pea starch and guar gum) was added to the PSGG-OA-Tween 20-glycerol mixture. These levels of film ingredients were optimized using Box-Behnken response surface design (Saberi et al., 2017). The emulsion was gelatinized at $90^{\circ} \mathrm{C}$ for $20 \mathrm{~min}$ on a hot plate with continuous stirring.

Once the lipids had melted, samples were homogenized for 4 min at $22000 \mathrm{rpm}$ using a T25 Ultra-Turrax (Ika, Staufen, Germany). After homogenization, the film solution was cooled to room temperature with slow magnetic stirring. The emulsion was prepared one day before use and was shown to be stable with no phase separation.

\subsection{Experimental design}

Five series of treatments were applied on oranges: (i) PSGG; (ii) PSGG-Sh; (iii) bilayer formulation of PSGG as an inner layer with Sh solution as an external layer (PSGG/Sh); (iv) CW (commercial wax, shellac based 'Citrus Gleam') and (v) distilled water acting as a control. Each treatment for each storage condition included 128 oranges with 8 oranges per plastic netted bag. There were four replicates per treatment with each bag considered a single replicate. Data were recorded before treatment (day 0) and at $7 \mathrm{~d}$ intervals (four removals) for up to four weeks storage at $20{ }^{\circ} \mathrm{C}$ and relative humidity $(\mathrm{RH})$ of $90-95 \%$, and logging the temperature 
and RH with calibrated TinyTag View 2 loggers. Another set of treated oranges was also stored for $1,2,3$, and 4 weeks at $5{ }^{\circ} \mathrm{C}$ and $90-95 \% \mathrm{RH}$, followed by one additional week at $20^{\circ} \mathrm{C}$ to simulate retail handling and marketing conditions.

\subsection{Fruit coating}

Each coating solution was sprayed uniformly on the whole fruit surface by using a paint sprayer (High Volume Low Pressure system, 500W Paint Sprayer, 909, Mooroolbark, Vic, Australia). The bilayer coatings were applied as follows: first the PSGG coating was applied and fruit were fan dried at room temperature for 2-3 min and then the Sh coating was applied. Then, all coated oranges were air-dried for $1 \mathrm{~h}$ at $20{ }^{\circ} \mathrm{C}$, labelled, weighed, and then randomly packed into experimental units. Fruits were destructively measured each week for up to four weeks at either $20{ }^{\circ} \mathrm{C}$ or $5{ }^{\circ} \mathrm{C}$. Four oranges from each replicate were assessed upon removal (when the fruit had reached room temperature) and the remaining four fruit were stored for the additional week at $20^{\circ} \mathrm{C}$.

\subsection{Fruit quality parameters}

\subsubsection{Weight loss}

Fruit weight loss was measured by weighing the same marked fruit, at the beginning of the experiment and at the end of each storage period. The results were presented as the percentage loss of initial weight (Rojas-Argudo et al., 2009).

\subsubsection{Fruit firmness}

A texture analyzer (Lloyd Instrument LTD, Fareham, UK) was used to determine firmness of fruit upon each removal. The maximum force $(\mathrm{N})$ was measured by compressing the fruit in the equatorial zone between two flat surfaces closing together at the rate of $1 \mathrm{~mm} \mathrm{~min}^{-1}$ to a 
depth of $2 \mathrm{~mm}$. The average of two reading points from each side of the fruit were recorded

157 (Cháfer et al., 2012).

\subsubsection{Respiration rate}

159 Respiration rate was measured by the method described by Pristijono et al. (2017a), where 6 160 oranges from each replicate were allocated into $500 \mathrm{~mL}$ hermetic glass jars with a septum in the lid at $20{ }^{\circ} \mathrm{C}$, and headspace gas sample $(1 \mathrm{~mL})$ was collected by a syringe after $1 \mathrm{~h}$, and transferred to an ICA40 series low-volume gas analysis system (International Controlled Atmosphere Ltd., Kent, UK). Respiration rate was expressed as $\mu \mathrm{g} \mathrm{CO}_{2} \mathrm{~kg}^{-1} \mathrm{~s}^{-1}$.

\subsubsection{Ethylene production}

Gas sample $(1 \mathrm{~mL})$ for analysis was taken $4 \mathrm{~h}$ after sealing the container as previous described for respiration. The concentration of ethylene was calculated by injecting the sample into a flame ionization gas chromatograph (Gow-Mac 580, Bridgewater NJ) fitted with a stainless steel column $(2 \mathrm{~m} \times 3.2 \mathrm{~mm}$ OD $\times 2.2 \mathrm{~mm}$ ID) packed with Porapak Q (80-100 mesh) (Altech, Sydney), with 110,90 and $70{ }^{\circ} \mathrm{C}$ as the operating temperature of the detector, column, and the injector, respectively. Nitrogen, hydrogen and air were used as carrier and combustion gases at as ng $\mathrm{C}_{2} \mathrm{H}_{4} \mathrm{~kg}^{-1} \mathrm{~s}^{-1}$ (Huque et al., 2013).

174 Color was assessed using the CIE L*, $a^{*}, b^{*}$ scale and a Minolta colorimeter (Minolta CR-400, 175 Osaka). The results were the means of three points on the fruit surface and expressed as Hue angle (Robles-Sánchez et al., 2013).

177 Hue $=\operatorname{arctangent}\left(\frac{b^{*}}{a^{*}}\right)$ 
179 Headspace ethanol $\left(\mathrm{g} \mathrm{L}^{-1}\right)$ and acetaldehyde $\left(\mathrm{mg} \mathrm{L}^{-1}\right)$ concentration in orange juice was determined according to Kumar et al. (2014). Ten $\mathrm{mL}$ aliquots of orange juice, extracted from

four different fruit in each bag, were transferred into $20 \mathrm{~mL}$ vials, sealed with crimp top fitted with a $2 \mathrm{~mm}$ rubber septum, and incubated at $30{ }^{\circ} \mathrm{C}$ for $10 \mathrm{~min}$ in a water bath. A one $\mathrm{mL}$ sample of the head space was injected in a gas chromatograph (Series 580, GOW MAC, Bethlehem, PA, USA) equipped with a flame ionization detector and a stainless steel $(1.2 \mathrm{~m} \times$ $3 \mathrm{~mm}$ ) filled with Porapak® QS 80/100 column, with nitrogen used as a carrier gas at $30 \mathrm{~mL}$ $\mathrm{min}^{-1}$, hydrogen at $19 \mathrm{~mL} \mathrm{~min}^{-1}$ and the air flow at $300 \mathrm{~mL} \mathrm{~min}{ }^{-1}$. The column, injector and detector temperatures were set at 142,164 and $163{ }^{\circ} \mathrm{C}$, respectively. A $10 \mathrm{~mL}$ of solution containing ethanol and acetaldehyde at $100 \mu \mathrm{L} \mathrm{L}^{-1}$ in $20 \mathrm{~mL}$ sealed vial was incubated at the same temperature and used as internal standards for quantity evaluations. The measurements for standard and samples were made in quadruplicate.

\subsubsection{Subjective fruit quality assessments}

\subsubsection{Peel pitting index (PPI)}

Fruit were visually scored to estimate the extent of peel pitting development after each storage time. Fruit were rated on a scale using the following scores: $0=$ no pits, $1=1-30 \%$ pitting, 2 $=31-50 \%$ pitting, $3=$ severe pitting or $>50 \%$ and the peel pitting index was measured according to the following formula (Alférez and Burns, 2004). The results were obtained by assessing all the fruit $(n=32)$ per treatment at each storage time.

$\mathrm{PPI}=\frac{\left.\sum \text { (rindstaining scale }(0-3) \times \text { number of fruit in each class }\right)}{\text { total number of fruit }}$ 
201 The proportion of the decay rate index was evaluated using the following scores: $0=$ no area

202 decay, $1=0-10 \%$ area decay, $2=11-30 \%$ area decay, $3=31-50 \%$ area decay and $4=51-$ $100 \%$ area decay (Wang et al., 2015). The fruit DRI was calculated for the total fruit $(\mathrm{n}=32)$ per treatment at each storage time as:

$\operatorname{DRI}(\%)=\frac{\sum(\text { decay grade }(0-4) \times \text { number of fruit at that grade })}{\text { highest level } \times \text { total number of fruit }} \times 100$

\subsubsection{Stem-end rind breakdown (SERB)}

207

The percentage of stem-end rind breakdown development was evaluated visually according to a four level scale: $0=$ no symptoms present; $1=$ slight or small symptoms; $2=$ moderate or noticeable symptoms of $30-50 \%$; and $3=$ severe symptoms or $>50 \%$ affected. The SERB was calculated by assessing all the fruit $(n=32)$ per treatment at each storage time as follows (Pristijono et al., 2017b):

$\operatorname{SERB}(\%)=\frac{\sum(\text { rot score }(0-3) \times \text { number of fruit at that grade })}{\text { highest level } \times \text { total number of fruit }} \times 100$

\subsubsection{Overall visual acceptability (OVA)}

Fruit visual acceptability was independently assessed based on a subjective four point scoring system; 4 = excellent (fresh and high quality fruit with glossy skin and no symptoms of dehydration, shriveling, and decay); 3 = good (marketable and acceptable fruit quality with slight shriveling and softness); 2 = not saleable but edible (fruit with moderate signs of shriveling, dryness, browning, and softness); and 1 = poor quality (fruit with severe signs of shriveling, significant softness, pitting, and decay) (Golding et al., 2015). The OVA was calculated as follows: 
221 OVA $(\%)=\frac{\sum(\text { rot score }(1-4) \times \text { number } \text { of fruit at that grade })}{\text { highest level } \times \text { total number of fruit }} \times 100$

222

223

224

225

226

227

229

230

231

232

233

234

235

236

237

238

239

240

241

242

243

\subsubsection{Sensory evaluation}

Fruit sensory evaluation was performed before treatment (day 0) and after one week at $20{ }^{\circ} \mathrm{C}$ following removal from cold storage. The panel involved twelve staff from NSW Department of Primary Industries, Ourimbah ( 6 females and 6 males), aged between 25 and 65 years old and who are familiar with citrus sensory evaluation. Fruit were brought to room temperature and hand-peeled, cut in half cross-wise with one half used for sensory analysis and the other half used for other quality measurements. Fruit were separated into individual segments and two segments from two different fruit were presented to panelists in coded $60 \mathrm{~mL}$ plastic cups. At each tasting session, panelists were given a rating sheet containing information on the evaluation procedure, in addition to general verbal instructions and individual clarifications as required. Panelists were requested to rate their degree of liking for the samples overall flavor on a 9-point hedonic scale ( 1 = "dislike extremely", 9 = "like extremely"). In addition, each panelist marked an unstructured $10 \mathrm{~cm}$ scale, with the anchor points 'none' and 'very strong' for off-flavor and 'not fresh at all' and 'very fresh' for freshness, and sensory data were recorded as distances $(\mathrm{mm})$ from the origin. Five samples at each tasting time were presented in a random sequence to prevent any positional bias. Panelists were required to cleanse their palate with a bite of low-salt saltine cracker, a sip of room temperature mineral water, and a small time lag between samples. The panelists average responses were considered for each attribute (Tietel et al., 2011).

\subsection{Statistical analysis}

All analyses were performed in quadruplicate. Sources of variation were storage time and treatment. The results were statistically assessed by analysis of variance (ANOVA) and Multiple Ranges Duncan's test to determine whether differences among treatments and storage 
times were significant at $P<0.05$ using the software SPSS (version 23, SPSS Inc., Chicago, IL, USA).

\section{Results and discussion}

\subsection{Weight loss}

249

Applied coatings significantly reduced water loss at most temperatures and storage times (Fig.

1), which is an expected and commercially desirable result. The influence of polysaccharide based coatings on the weight loss is probably associated with the existence of hydroxyl groups creating hydrogen bonds both inside the coating matrix and with the cuticle on the peel, which mostly consists of cutin, a polyester polymerized from hydroxylated fatty acids (Arnon et al., 2015; Koch and Ensikat, 2008).

Upon removal from storage at $5{ }^{\circ} \mathrm{C}$, water loss from non-coated fruit was always greater than the treated fruit, but with the additional week at $20^{\circ} \mathrm{C}$, water loss increased in all treatments. Similar results were observed in fruit stored constantly at $20^{\circ} \mathrm{C}$. In general, the addition of the Sh into PSSGG resulted in lower fruit weight loss, suggesting greatest benefit than the bilayer PSGG/Sh coating due to its likely higher moisture barrier capacity. The apparent synergistic effect between glycerol, Tween-20, and OA in the blended composite coatings is reported to result in a more compact and homogenous matrix (Rodríguez et al., 2006), reduce pores and cracks of films (García et al., 1999), and consequently decrease fruit weight loss in mandarin fruit (Rojas-Argudo et al., 2009). At constant $20{ }^{\circ} \mathrm{C}$ storage, all coatings reduced water loss after two weeks storage with similar trends noted at the $5{ }^{\circ} \mathrm{C}$ followed by one week at $20{ }^{\circ} \mathrm{C}$ storage. 

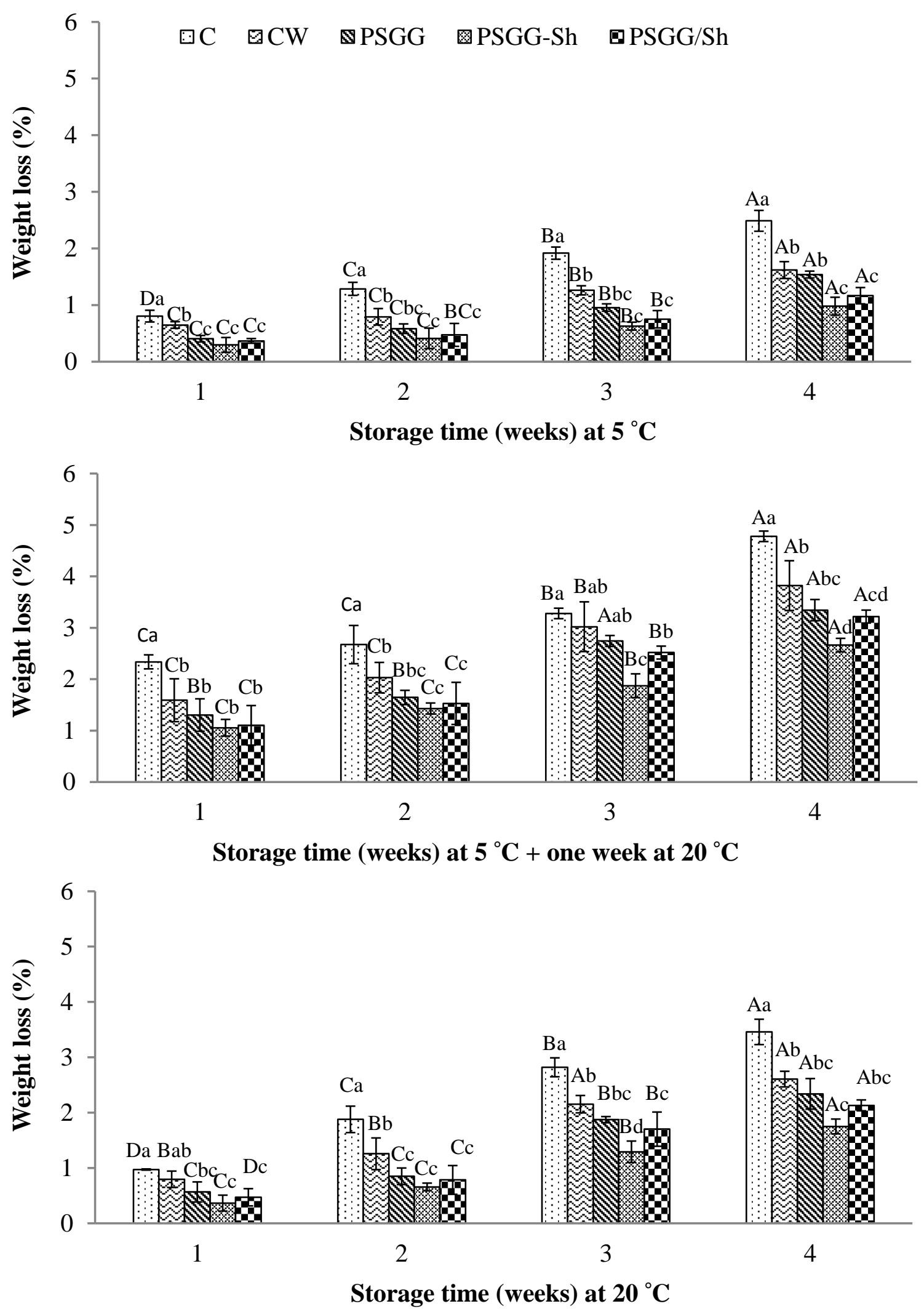

Fig. 1. Weight loss of 'Valencia' oranges stored at different storage conditions for four weeks as affected by various coatings treatments. Each bar represents the means of four replicates of 8 fruit each $(n=32) \pm$ standard error. The different lowercase superscript letters in the same storage time indicate significant differences within different coating treatments according to Duncan's test $(P<0.05)$. The different uppercase superscript letters in the same coating treatment indicate significant differences within different storage time according to Duncan's test $(P<0.05)$. 
273 Fruit treated with the blended composite PSGG-Sh coating were significantly firmer than

\subsection{Fruit firmness} untreated control at most storage times and temperatures except at one week storage at $5{ }^{\circ} \mathrm{C}$ in which there was little treatment effects (Fig. 2). This related generally to lower weight loss levels for the same treatment as described above. The loss of fruit firmness for PSGG-Sh coated fruits after four weeks storage period at constant $5{ }^{\circ} \mathrm{C}$, at $5{ }^{\circ} \mathrm{C}$ followed by $7 \mathrm{~d}$ at $20{ }^{\circ} \mathrm{C}$, and constant $20{ }^{\circ} \mathrm{C}$ was $0.9 \%, 4 \%$, and $2 \%$, respectively, with respect to the initial force value of fruit before treatment $(46.70 \pm 3.33 \mathrm{~N})$, whereas the loss in firmness for untreated fruit stored under the same conditions were $5 \%, 15 \%$ and $9 \%$. The firmness retention of PSGG coating alone was similar to that of $\mathrm{CW}$ in all storage assessments. Moreover, in spite of the good weight loss inhibition presented by the bilayer PSGG/Sh coating, this coating showed similar firmness losses compared with single layer PSGG coating during storage. This may be explained by mechanical tensile strength attributes of PSGG film (Saberi et al., 2016a).

The loss of fruit firmness is influenced by the water loss which is considered as main parameter for texture changes (Del-Valle et al., 2005). In this experiment, the reduction in firmness losses with the coatings was probably due to the restriction of moisture loss and the moisture migration from the cells to the surrounding atmosphere through transpiration (Mahfoudhi and Hamdi, 2015). 

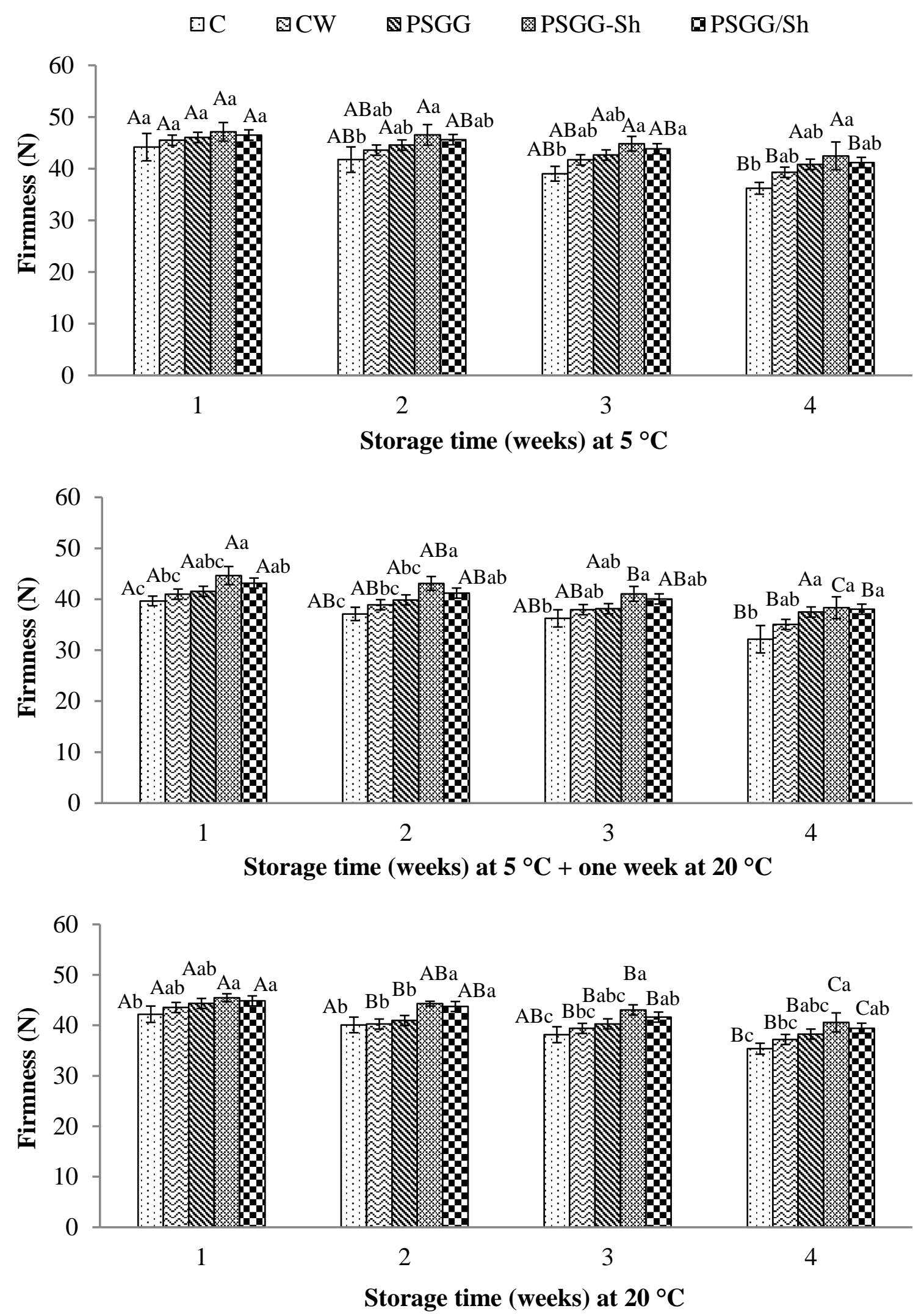

Fig. 2. Firmness of 'Valencia' oranges stored at different storage conditions for four weeks as affected by various coatings treatments. Each bar represents the means of four replicates of 8 fruit each $(n=32) \pm$ standard error. The different lowercase superscript letters in the same storage time indicate significant differences within different coating treatments according to Duncan's test $(P<0.05)$. The different uppercase superscript letters in the same coating treatment indicate significant differences within different storage time according to Duncan's test $(P<$ $0.05)$. 


\subsection{Respiration rate}

To estimate the effect of polysaccharide based coatings on respiration rate of oranges during different storage temperatures, $\mathrm{CO}_{2}$ concentration in the headspace was calculated (Fig. 3). The fruit respiration rate was $13.93 \pm 0.72 \mu \mathrm{g} \mathrm{CO}_{2} \mathrm{~kg}^{-1} \mathrm{~s}^{-1}$ at the beginning of the experiment and it decreased in all treatments after storage at $5{ }^{\circ} \mathrm{C}$ and $20{ }^{\circ} \mathrm{C}$. Citrus are considered a nonclimacteric fruit, i.e. ethylene production and respiration rates generally do not substantially increase during ripening and senescence (Wills and Golding, 2016).

Coated oranges generally had lower respiration rate than the uncoated control fruit (Fig. 3), likely due to the modification of internal gas atmosphere by the coatings (Cisneros- Zevallos and Krochta, 2002). Similar observations have been described by Arnon et al. (2015), Valencia-Chamorro et al. (2009), and Cháfer et al. (2012) in oranges coated with polysaccharide based edible coatings. In this experiment, the incorporation of hydrophobic compounds (oleic acid and shellac) into the coating formulation resulted in decreases in the respiration rates of treated fruit, such that the PSGG with Sh coated oranges had consistently lower respiration rates than the commercial wax and the untreated control fruit at all storage conditions. Similarly, the respiration rate of mandarins and oranges coated by hydroxypropyl methylcellulose edible coatings containing oleic acid and shellac has been shown to decrease compared to untreated control fruit (Navarro-Tarazaga et al., 2008; Valencia- Chamorro et al., 2010).

The addition of a shellac layer on PSGG coating generally resulted in lower respiration rates than those measured for oranges coated by single layer PSGG coatings. A similar trend of reduced respiration rate upon application of the LBL method was shown in previous studies with citrus fruit (Arnon et al., 2015; Poverenov et al., 2014). 

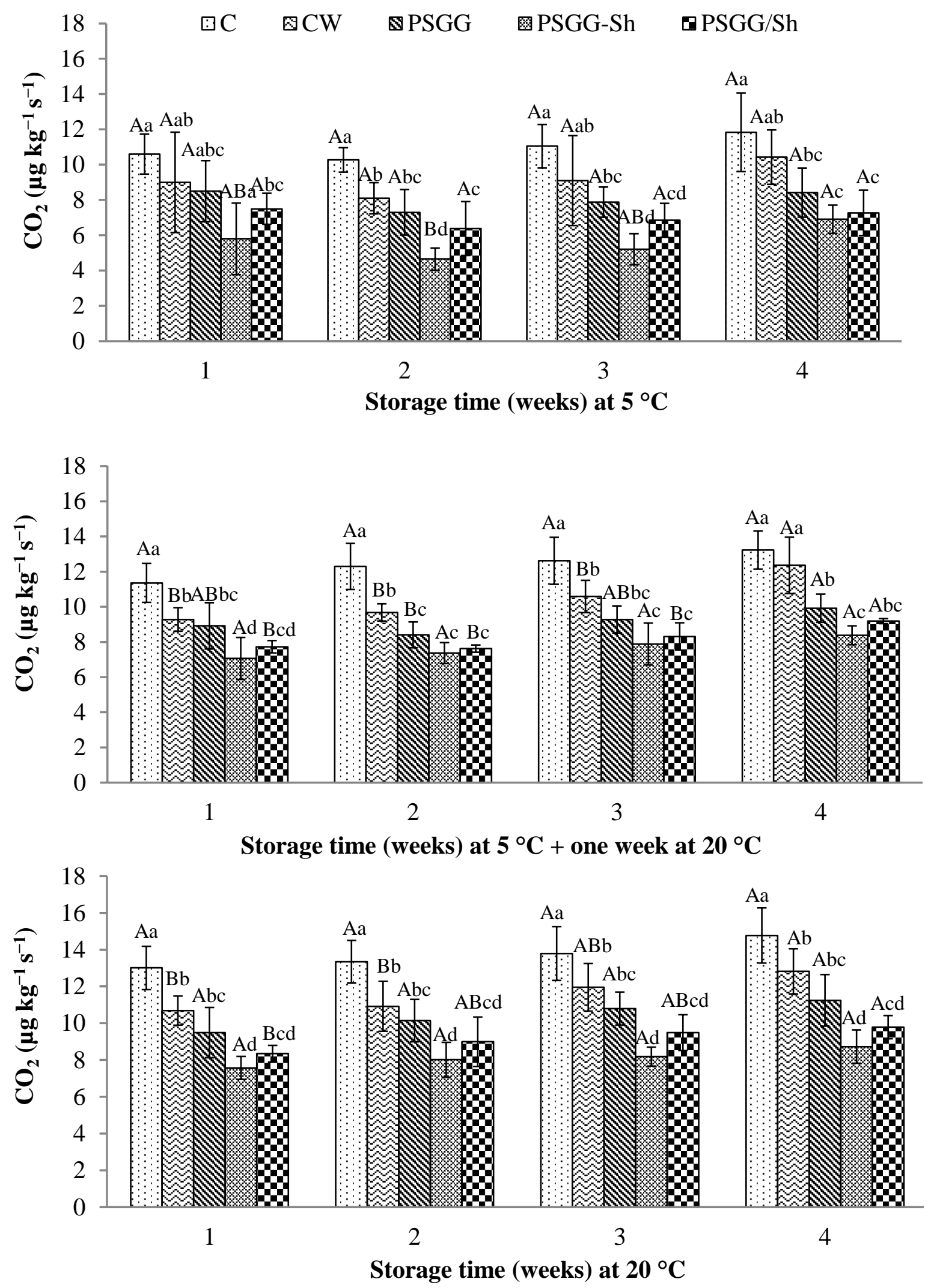

Fig. 3. Respiration rate of 'Valencia' oranges stored at different storage conditions for four weeks as affected by various coatings treatments. Each bar represents the means of four replicates of 8 fruit each $(n=32) \pm$ standard error. The different lowercase superscript letters in the same storage time indicate significant differences within different coating treatments according to Duncan's test $(P<0.05)$. The different uppercase superscript letters in the same coating treatment indicate significant differences within different storage time according to Duncan's test $(P<0.05)$. 
331 Ethylene production was $4.92 \pm 0.32 \mathrm{ng} \mathrm{C}_{2} \mathrm{H}_{4} \mathrm{~kg}^{-1} \mathrm{~s}^{-1}$ at the beginning of the experiment and generally increased during storage (Fig. 4). However, ethylene production in either uncoated or coated oranges did not exceed $32 \mathrm{ng} \mathrm{C}_{2} \mathrm{H}_{4} \mathrm{~kg}^{-1} \mathrm{~s}^{-1}$. That was expected as citrus are nonclimacteric fruit and the ethylene production rate generally do not considerably increase during storage (Wills and Golding, 2016). In this experiment, coated fruit generally had lower ethylene production rates than uncoated ones as expected. In general, fruit coated with PSGG-Sh produced less ethylene than fruit from most of the other treatments.

\subsection{Skin color}

There were no significant changes in the peel color as described by the hue angle and measured with a color meter (data not shown). The coatings treatments did not significantly affect fruit skin color during storage. 

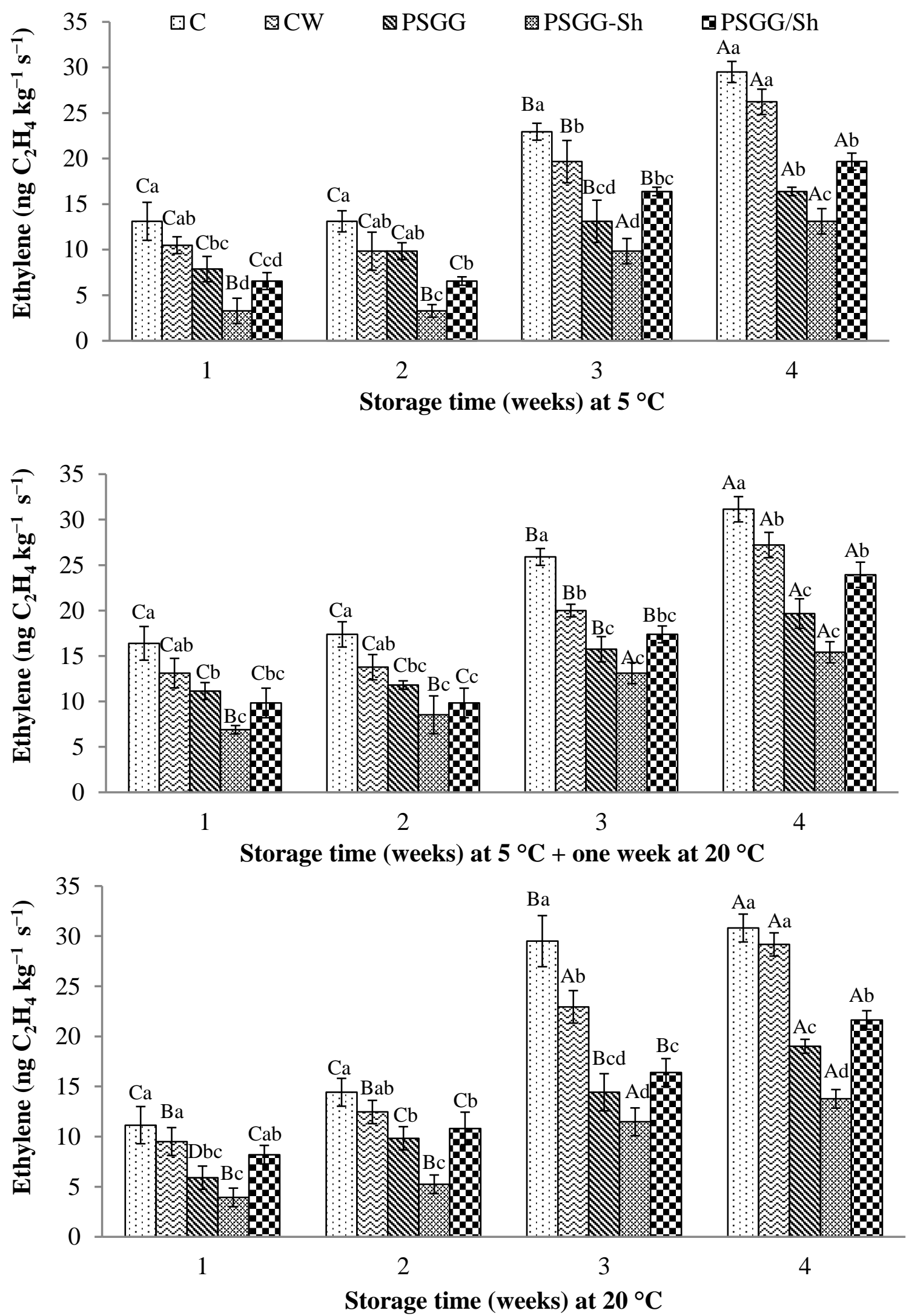

Fig. 4. Ethylene production of 'Valencia' oranges stored at different storage conditions for four weeks as affected by various coatings treatments. Each bar represents the means of four replicates of 8 fruit each $(n=32) \pm$ standard error. The different lowercase superscript letters in the same storage time indicate significant differences within different coating treatments according to Duncan's test $(P<0.05)$. The different uppercase superscript letters in the same coating treatment indicate significant differences within different storage time according to Duncan's test $(P<0.05)$. 
358 The concentrations of ethanol and acetaldehyde in the headspace of the juice of 'Valencia' 359 orange fruit at the beginning of the experiment were $0.13 \pm 0.02 \mathrm{~g} \mathrm{~L}^{-1}$ and $0.95 \pm 0.12 \mathrm{mg} \mathrm{L}^{-1}$, 360 respectively (Figs. 5 and 6). In all cases, the ethanol and acetaldehyde concentrations increased during storage at both $5{ }^{\circ} \mathrm{C}$ and $20^{\circ} \mathrm{C}$ storage. The production of both volatiles naturally occurs in fruit and their increased levels have been associated with off-flavors in citrus fruit (Hagenmaier, 2002).

Higher levels of ethanol have been generally reported in coated oranges than in the uncoated fruit, confirming the development of a modified atmosphere inside the fruit (ValenciaChamorro et al., 2009). Though, ethanol concentration in coated oranges did not surpass the maximum set up at $2000 \mathrm{mg} \mathrm{L}^{-1}$ as the concentration of off-flavor build-up risk (Rojas-Argudo et al., 2009). The ethanol concentrations in the juice of bilayer PSGG/Sh-coated fruit were significantly higher than in the juice of CW-coated fruit after prolonged cold storage followed by further one week storage at $20^{\circ} \mathrm{C}$. This can be likely attributed to the lower gas permeability that bilayer coatings created in the fruit. It has been reported that citrus fruit coated with shellacbased commercial waxes commonly have higher ethanol concentrations than uncoated samples (Contreras- Oliva et al., 2012). Variations in the ethanol content between the experimental coatings single layer PSGG and blended composite PSGG-Sh, and the uncoated oranges were similar, especially after two weeks storage at $20^{\circ} \mathrm{C}$. Moreover, there was generally little significant differences between coatings treatments on acetaldehyde levels in 'Valencia' orange juice especially in weeks one and two; however, bilayer and CW coatings generally resulted in higher acetaldehyde content in orange juice as the storage period increased. 


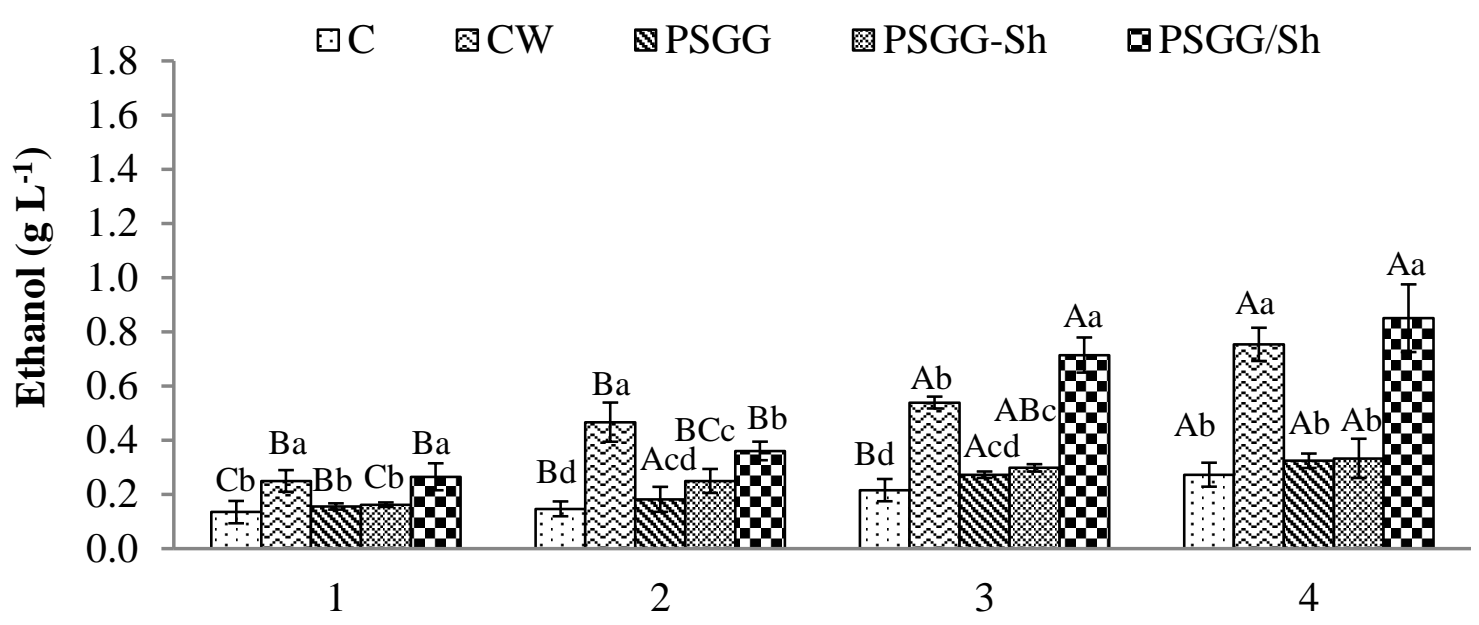

Storage time (weeks) at $5^{\circ} \mathrm{C}$
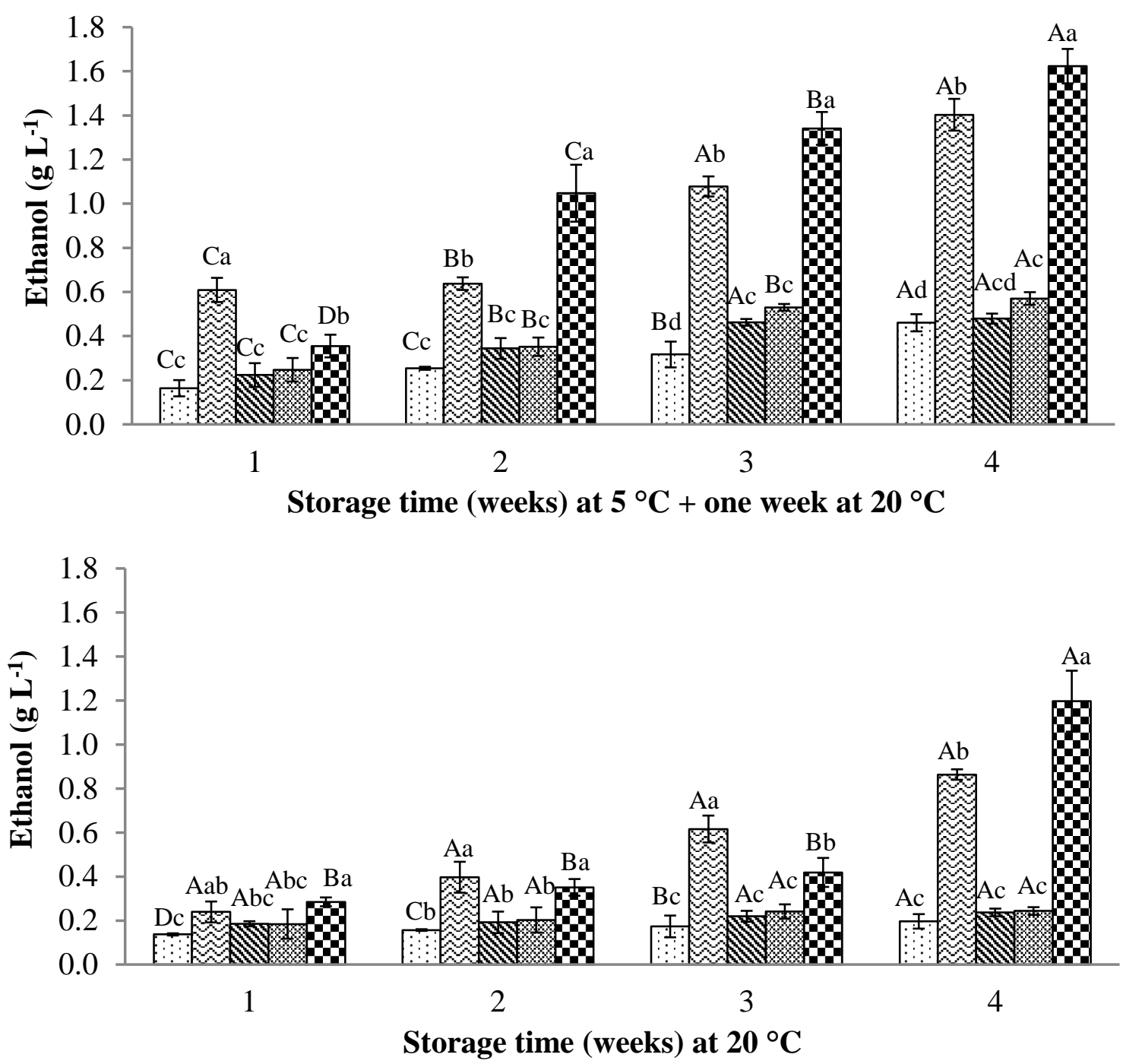

Fig. 5. Ethanol concentration in the juice of 'Valencia' oranges stored at different storage conditions for four weeks as affected by various coatings treatments. Each bar represents the means of four replicates of 8 fruit each $(\mathrm{n}=32) \pm$ standard error. The different lowercase superscript letters in the same storage time indicate significant differences within different coating treatments according to Duncan's test $(P<0.05)$. The different uppercase superscript letters in the same coating treatment indicate significant differences within different storage time according to Duncan's test $(P<0.05)$. 

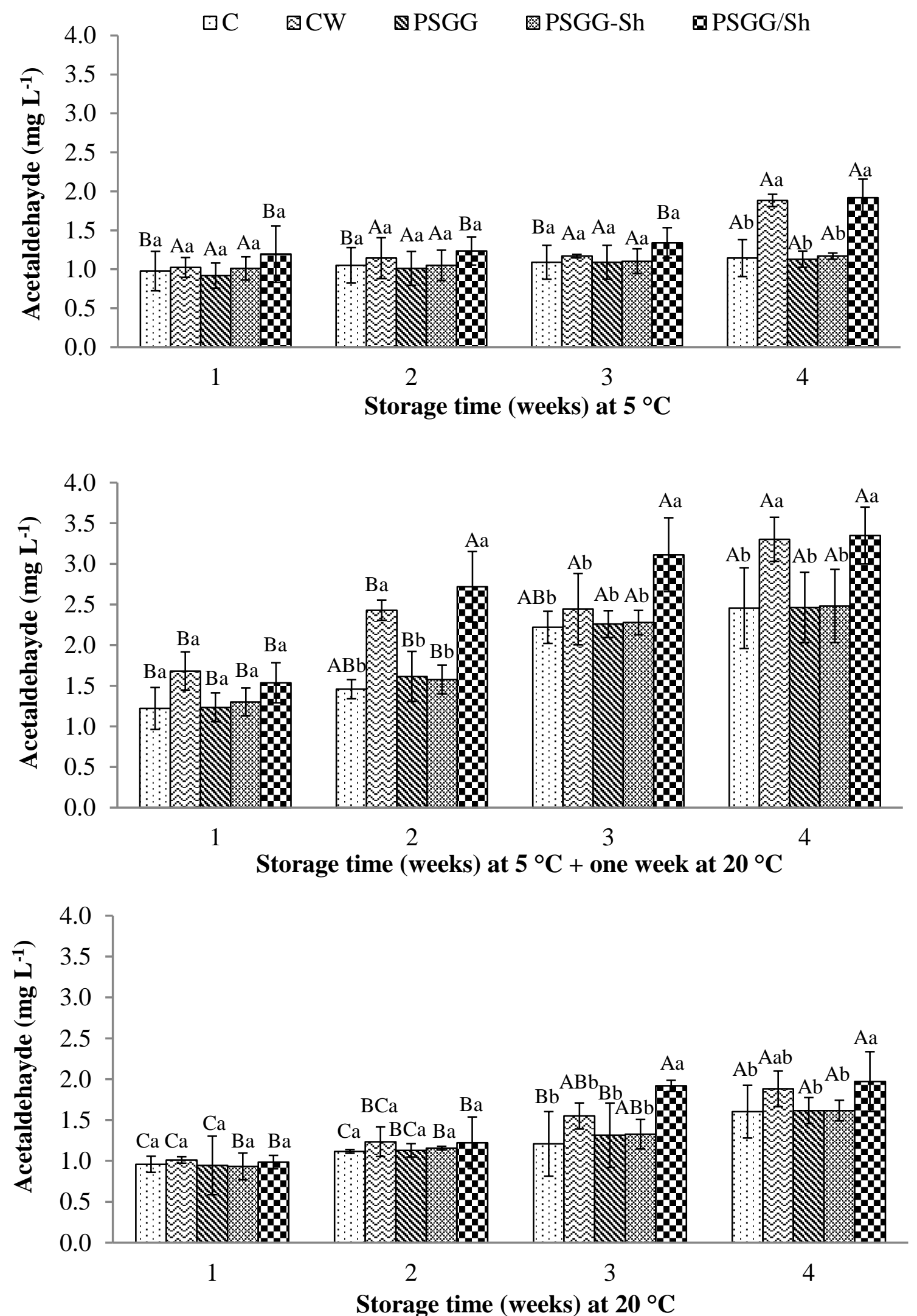

Fig. 6. Acetaldehyde concentration in the juice of 'Valencia' oranges stored at different storage conditions for four weeks as affected by various coatings treatments. Each bar represents the means of four replicates of 8 fruit each $(n=32) \pm$ standard error. The different lowercase superscript letters in the same storage time indicate significant differences within different coating treatments according to Duncan's test $(P<0.05)$. The different uppercase superscript letters in the same coating treatment indicate significant differences within different storage time according to Duncan's test $(P<0.05)$. 


\subsection{Subjective fruit quality assessments}

The incidence of peel pitting in coated and uncoated 'Valencia' oranges generally increased with longer storage time (Fig. 7). Higher temperature during storage favored the incidence of peel pitting in 'Valencia' oranges. The uncoated fruit showed the highest PPI value, which increased from 0.06 to 0.37 and 0.09 to 0.44 during four weeks storage at $5{ }^{\circ} \mathrm{C}$ and ambient temperature, respectively. The rate of increase in the PPI varied among fruit treated with various coatings stored at different temperatures. No peel pitting was observed in fruit treated with PSGG-Sh coating after three weeks storage at $5{ }^{\circ} \mathrm{C}$. By four weeks storage at $5{ }^{\circ} \mathrm{C}$ the PPI of fruit coated with PSGG-Sh was 0.09; while that of fruit coated with PSGG and bilayer PSGG/Sh was 0.13 and 0.28 , respectively. Transferring fruit from $5{ }^{\circ} \mathrm{C}$ followed by one week storage at $20{ }^{\circ} \mathrm{C}$ increased postharvest peel pitting, possibly because of the increased rate of dehydration (Alférez and Burns, 2004). However, it was hard to distinguish the difference between peel pitting and chilling injury in fruit storage at $5{ }^{\circ} \mathrm{C}$ and with the additional storage for one week at $20^{\circ} \mathrm{C}$, and both considered as physiological disorder and results were reported together. Peel pitting developed in all fruit after two weeks storage at $5{ }^{\circ} \mathrm{C}$ followed by one week storage at $20^{\circ} \mathrm{C}$.

In general, $\mathrm{CW}$ and bilayer PSGG/Sh coatings resulted in more pitting on the coated fruit surface, however the PPI was lower in bilayer coated fruit. Application of more gas-permeable coatings along with storage at cool temperature appeared to have postponed postharvest peel pitting in this study. These results indicate that faster water permeability and therefore a faster water position adjustment in the albedo and flavedo of the fruit peel may alleviate peel pitting development (Cronjé et al., 2017). Moreover, decreases in internal $\mathrm{O}_{2}$ and increases in internal $\mathrm{CO}_{2}$ in coated fruit can be effective in reducing peel pitting disorder, although the relationship between the level of pitting and internal $\mathrm{CO}_{2}$ and $\mathrm{O}_{2}$ levels in fruit may not be as strong (Alférez and Burns, 2004; Petracek et al., 1998). Regardless of higher weight loss value in fruit coated 
with PSGG compared with bilayer coated fruit, subsequent dehydration of orange peel coated with PSGG did not appear to be enough to stimulate postharvest peel pitting. These results suggest that a variety of factors including peel maturity and senescence may be involved in postharvest peel pitting in 'Valencia' oranges.

Decay due to natural infection during the whole storage was relatively low as fruit were sanitized with a fungicide (Fig. 7). The coatings decreased DRI compared with control fruit in all storage conditions. The films and coatings can suspend decay by reducing senescence, which causes more susceptibility to pathogenic infection in produce due to damage of cellular or tissue integrity (Tanada-Palmu and Grosso, 2005). No visible sign of decay in coated or control fruit was observed until three weeks of the storage period at $5{ }^{\circ} \mathrm{C}$ (Fig. 7). Fruit treated with PSGG-Sh coating remained disease free during four weeks at $5{ }^{\circ} \mathrm{C}$ and three weeks at 20 and transferring to ambient temperature with further storage of one week generally increased DRI in fruit from most treatments. At the first week of transferring fruit from $5{ }^{\circ} \mathrm{C}$ to $20{ }^{\circ} \mathrm{C}$, $2.3 \%$ of the control fruit decayed and DRI increased to $9.4 \%$ at the end of storage time.

The incidence of SERB in fruit maintained at high temperature was higher compared with those stored at low temperature and control fruit indicated higher SERB value (Fig. 8). Transfer of fruit to $20^{\circ} \mathrm{C}$ after one week storage at $5{ }^{\circ} \mathrm{C}$ also caused a noticeable increase in the occurrence of SERB. Fruit coated by PSGG and PSGG-Sh did not show any sign of SERB after three weeks storage at $5{ }^{\circ} \mathrm{C}$ and two weeks storage at $20{ }^{\circ} \mathrm{C}$ (Fig. 8).

The OVA of the control and coated fruit decreased throughout storage time. Fruit coated by PSGG-Sh showed the highest OVA followed by PSGG and bilayer PSGG/Sh-coated fruit at all storage circumstances (Fig. 8). 

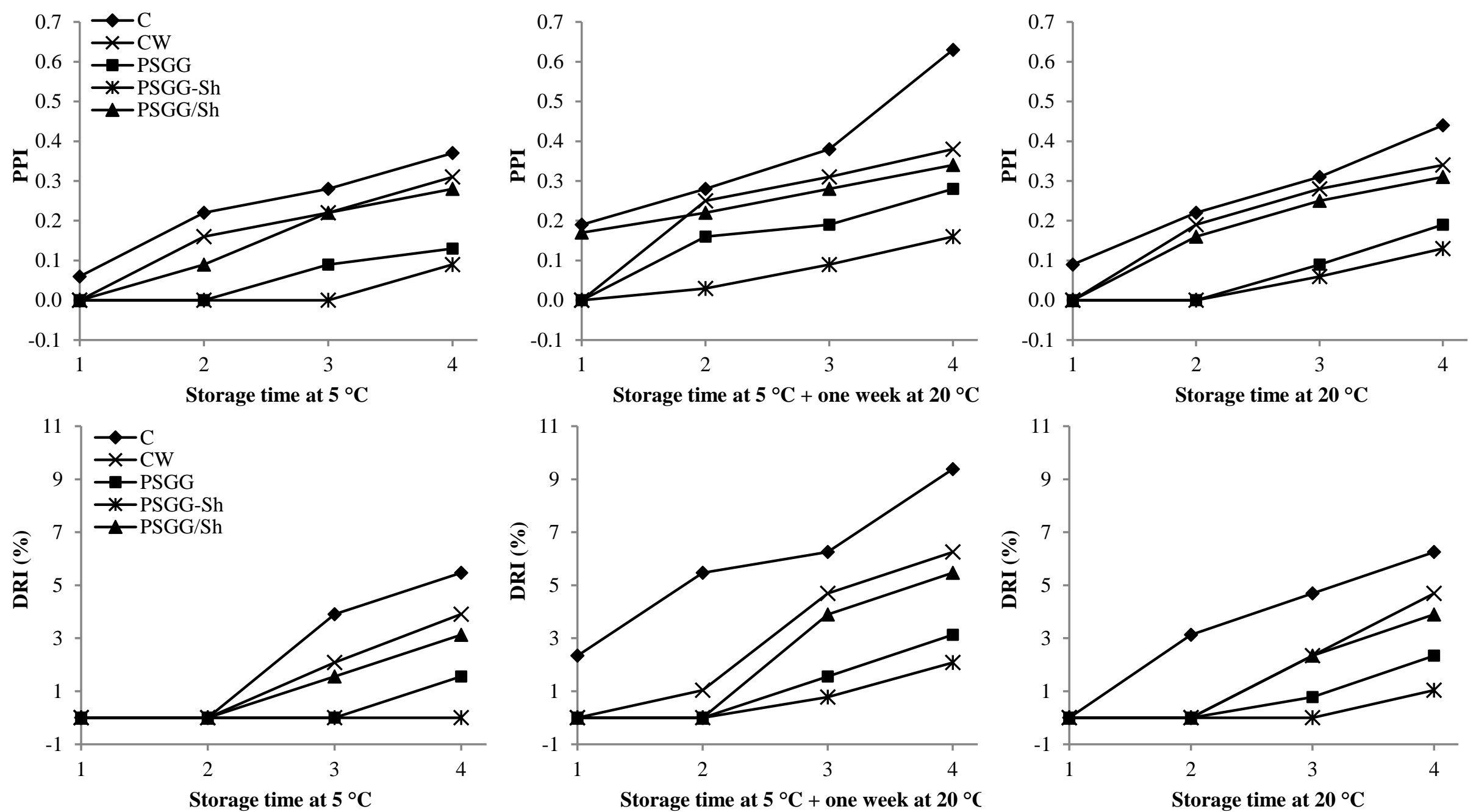

Fig. 7. Peel pitting index (PPI) and percentage of fruit decay rate index (DRI) of coated and uncoated 'Valencia' oranges stored at different storage conditions for four weeks as affected by various coatings treatments. Each point is total value for $\mathrm{n}=32$ fruit per treatment at each storage time. 

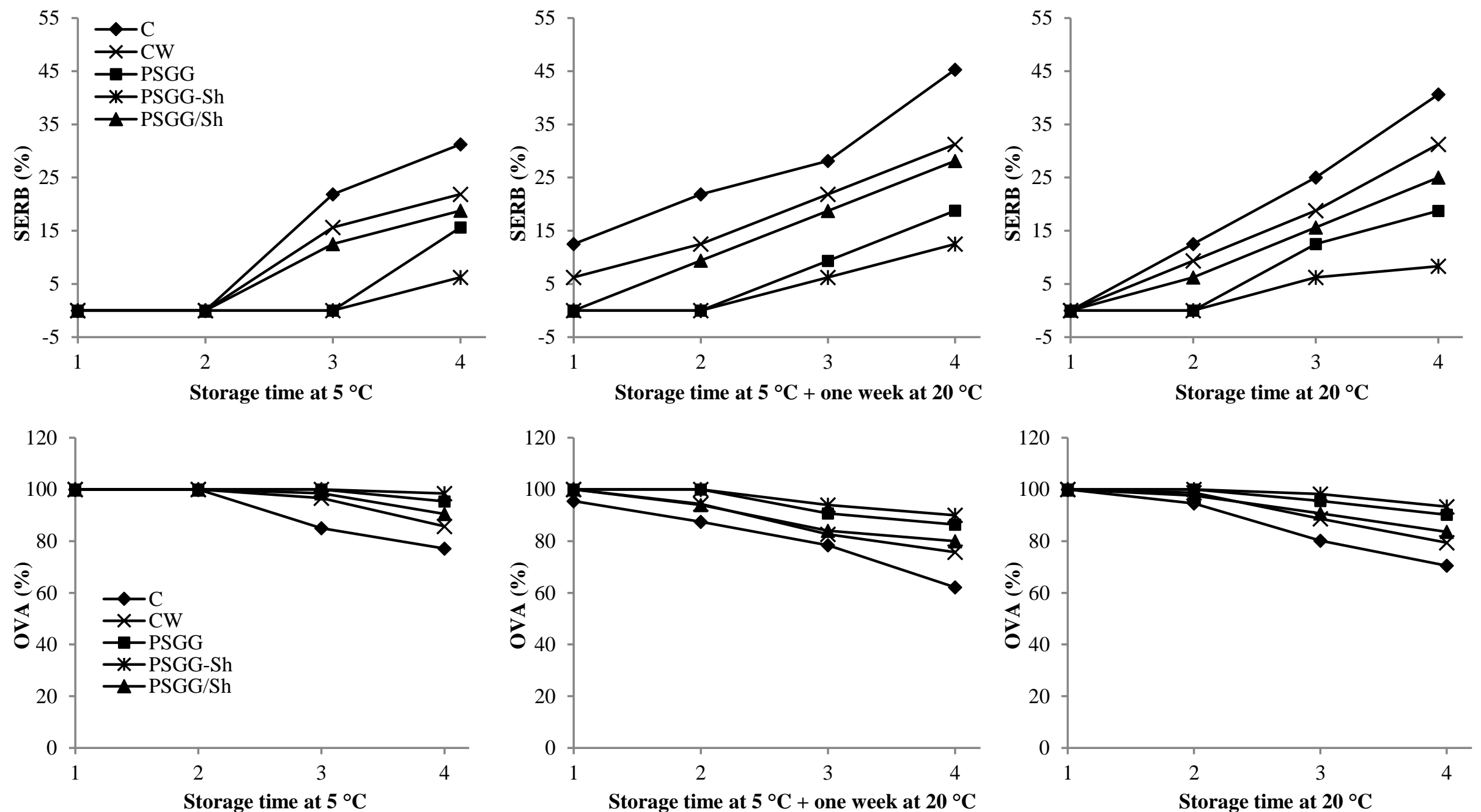

Fig. 8. The percentage of stem-end rind breakdown (SERB) and overall visual acceptability (OVA) of coated and uncoated 'Valencia' oranges stored at different storage conditions for four weeks as affected by various coatings treatments. Each point is total value for $\mathrm{n}=32$ fruit per treatment at each storage time. 
449 Overall flavor scores from fruit stored at $5{ }^{\circ} \mathrm{C}$ for four weeks and then held for one week at 20

$450{ }^{\circ} \mathrm{C}$ were significantly higher in PSGG and blended composite PSGG-Sh coated compared to 451 the uncoated control fruit (Fig. 9A). In contrast, there were no differences in overall flavor 452 between treated and untreated fruit for the first three weeks of storage at $5{ }^{\circ} \mathrm{C}$. Overall flavor evaluation of uncoated oranges reduced with storage time, from 7.2 before storage to 4.4 at the end of the storage. Although only a relatively small sensory panel was used, these results provide an indication of what consumer likeability would be for both treated and untreated oranges at a likely consumption stage of the fruit.

The levels of off-flavor detected in fruit stored for 2,3 and 4 weeks at $5{ }^{\circ} \mathrm{C}$ and then held for 1 week at $20{ }^{\circ} \mathrm{C}$ were significantly lower in both the PSGG and PSGG-Sh coated fruit (and similar to control fruit) compared to CW and to PSGG/Sh (at 3 and 4 weeks) coated fruit (Fig. 9B), the results were correlated with the ethanol and acetaldehyde levels determined in respective coated fruits. Treatment differences in off-flavor were not significant in fruit stored for one week at $5{ }^{\circ} \mathrm{C}$ and then held for one week at $20{ }^{\circ} \mathrm{C}$. Off-flavor evaluation of uncoated oranges increased with storage time, from 0 before storage to 2.2 at the end of the storage. There was a general trend of off-flavor increasing with storage time for most treatments (Fig. 9B).

Following 3 and 4 weeks storage at $5{ }^{\circ} \mathrm{C}$ plus one week at $20{ }^{\circ} \mathrm{C}$, the fruit coated with single layer PSGG and blended composite PSGG-Sh were perceived as 'fresher' than the untreated control fruit (Fig. 9C). There were no differences in 'freshness' of any treatment for the first two weeks of storage at $5{ }^{\circ} \mathrm{C}$ followed by one week at $20^{\circ} \mathrm{C}$. Freshness evaluation of uncoated oranges reduced with storage time from 8.0 before storage to 4.7 at the end of the storage. 
471 Applied wax or other surface coatings can alter the internal atmosphere in citrus fruit 472 throughout the supply chain, leading to the accumulation of anaerobic metabolites such as 473 ethanol and acetaldehyde, which have been associated with poor flavor in a number of studies 474 (Baldwin et al., 1995; Obenland et al., 2008; Ummarat et al., 2015). Both applied coatings and 475 cold storage are also reported to change a number of flavor-related aroma volatiles in citrus 476 fruit, and similar effects could have contributed to the results found in this study. For example, 477 compared with uncoated fruit, 'Valencia' oranges treated with a commercial shellac-based wax 478 and stored at 16 or $21{ }^{\circ} \mathrm{C}$ for up to $56 \mathrm{~d}$ had higher concentrations of ethanol, ethyl butanoate, 479 ethyl acetate, and alpha-pinene as time in storage increased, whereas levels of valencene, alpha480 terpineol, and hexanol were generally lower, especially at the higher storage temperature 481 (Baldwin et al., 1995). Likewise, flavor quality (i.e. both overall flavor likeability and 482 freshness) of 'Navel' oranges stored at $5{ }^{\circ} \mathrm{C}$ for 3 or 6 weeks followed by $4 \mathrm{~d}$ at $13{ }^{\circ} \mathrm{C}$ and $3 \mathrm{~d}$ 483 at $20{ }^{\circ} \mathrm{C}$ was reduced compared to non-stored fruit presumably due to lower levels of limonene 484 and higher levels of ethyl butanoate, ethyl hexanoate and other four aroma-active compounds 485 (Obenland et al., 2008). 


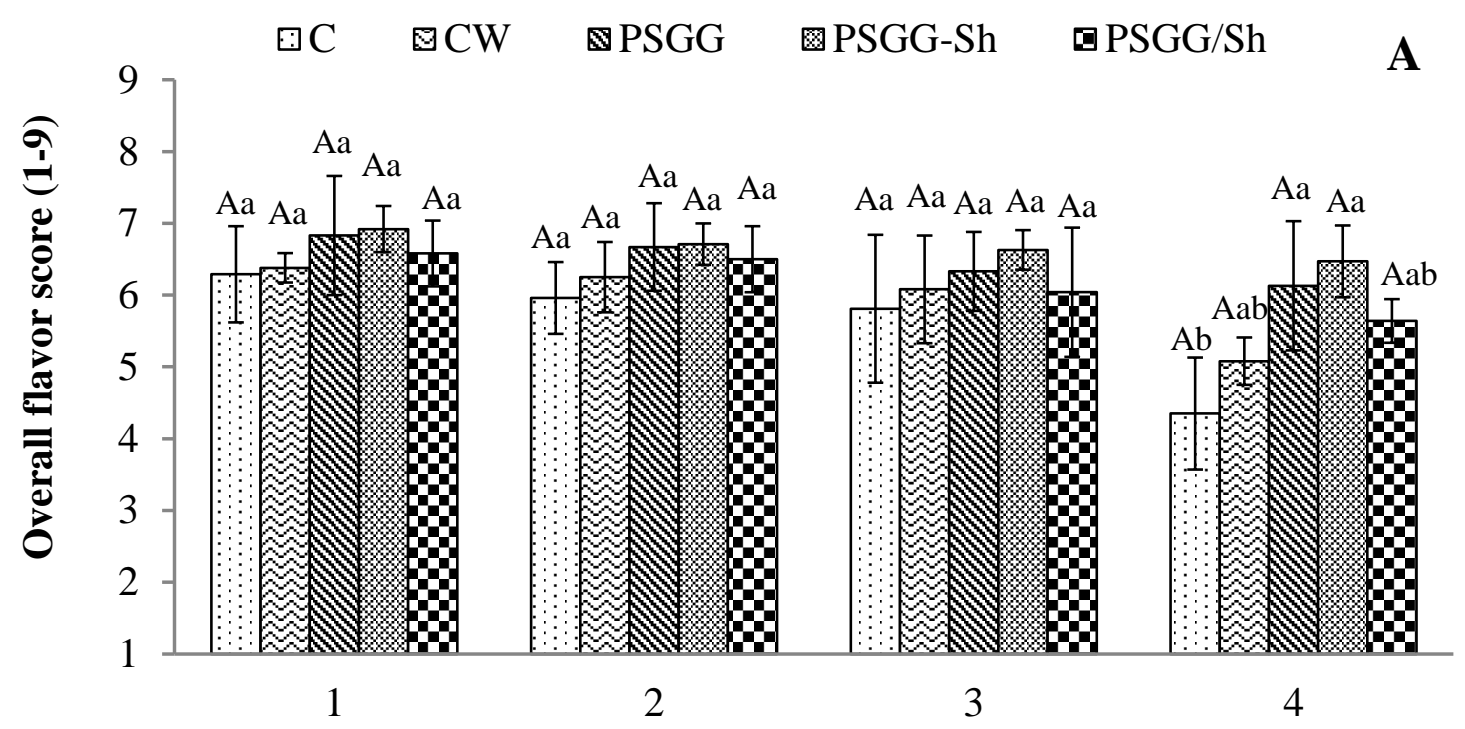

Storage time (weeks) at $5^{\circ} \mathrm{C}+$ one week at $20^{\circ} \mathrm{C}$

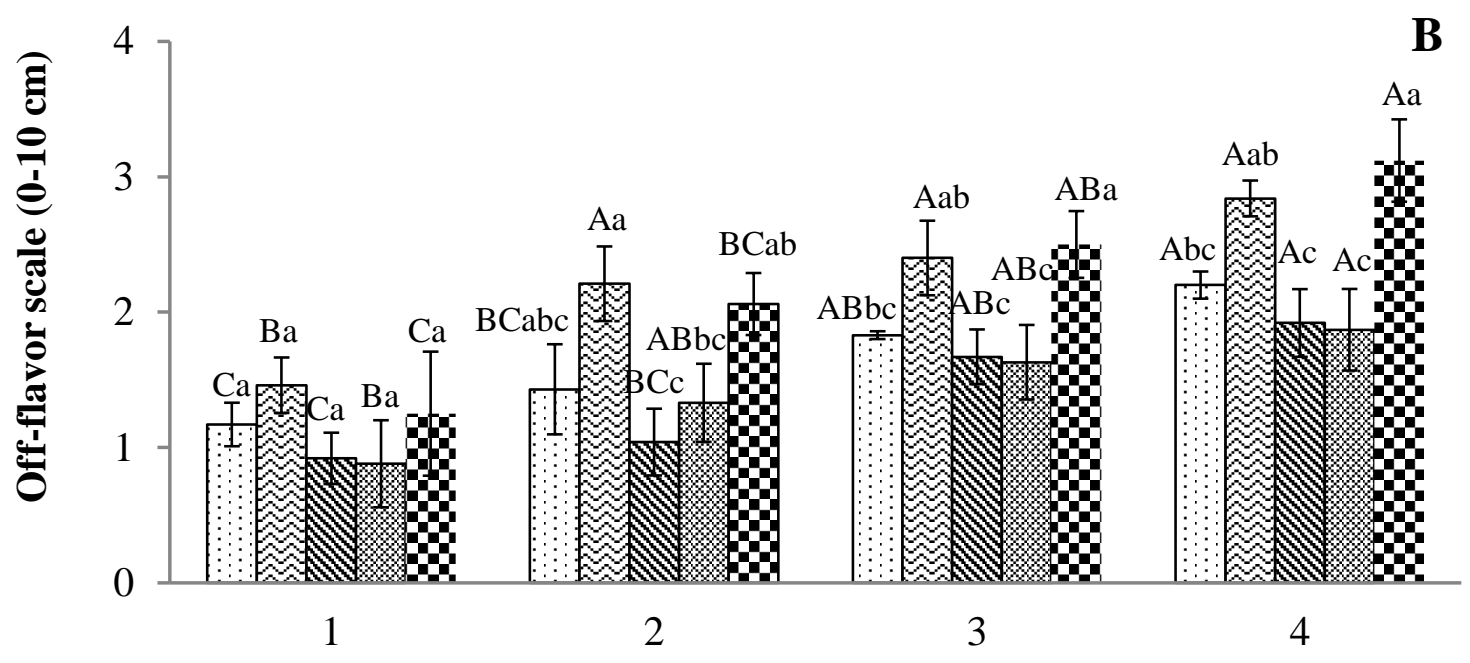

Storage time (weeks) at $5^{\circ} \mathrm{C}+$ one week at $20 \mathrm{C}^{\circ}$

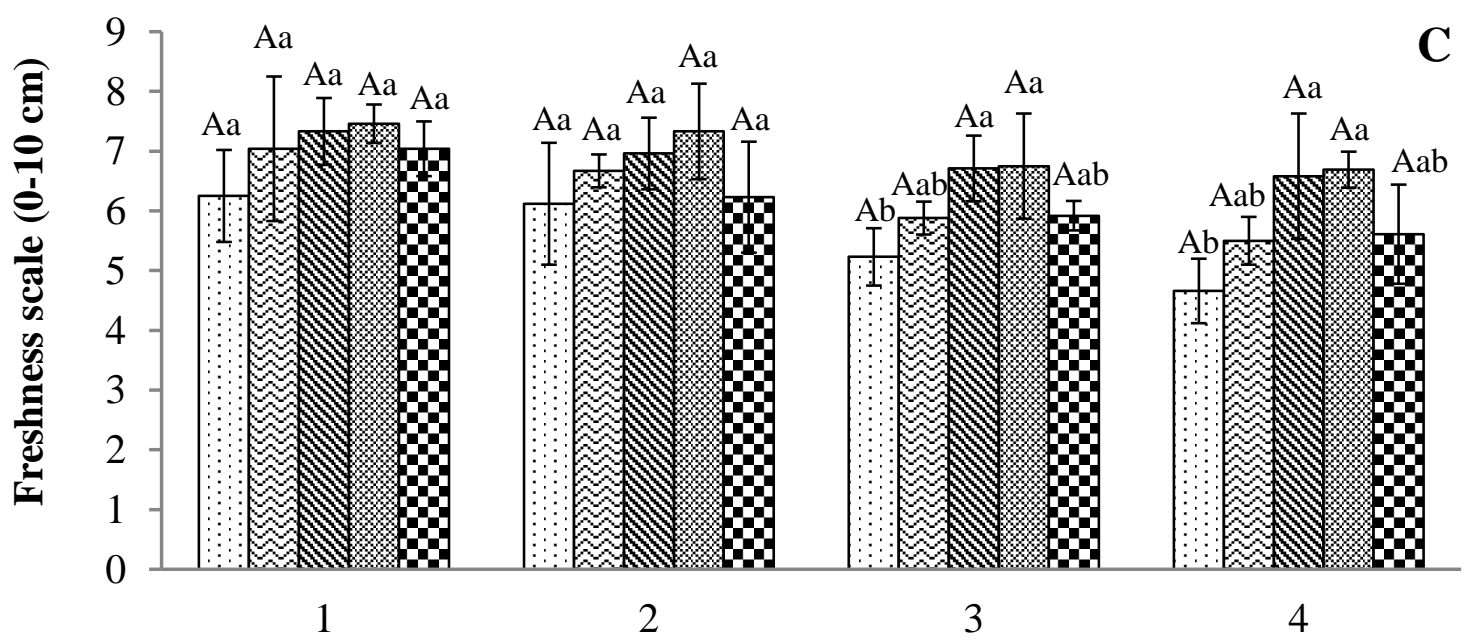

Storage time (weeks) at $5{ }^{\circ} \mathrm{C}+$ one week at $20{ }^{\circ} \mathrm{C}$

Fig. 9. Sensory evaluation of 'Valencia' oranges stored at $5{ }^{\circ} \mathrm{C}$ for four weeks plus one week at $20{ }^{\circ} \mathrm{C}$ as affected by various coatings treatments. (A): Overall flavor, (B): Off-flavor, and (C): Freshness. The values represent means of twelve replicates \pm standard error. The different lowercase superscript letters in the same storage time 
indicate significant differences within different coating treatments according to Duncan's test $(P<0.05)$. The different uppercase superscript letters in the same coating treatment indicate significant differences within different storage time according to Duncan's test $(P<0.05)$. Overall flavor was rated on a 9-point hedonic scale (1=“dislike extremely", 9="like extremely"). Off-flavor and freshness were assessed based on an unstructured 10 $\mathrm{cm}$ scale, with the anchor points 'none' and 'very strong' for off-flavor, and 'not fresh at all' and 'very fresh' for freshness.

\section{Conclusion}

The results showed the benefit of applying edible coatings on the maintenance of fruit quality during storage and shelf life. The lower levels of respiration rates in coated fruit reflected the capability of the coating to modify the internal atmosphere of fruit as a protective gas barrier.

The incorporation of lipid compounds into the PSGG coatings resulted in the optimum performance in reducing fruit respiration rate, ethylene production, weight and firmness loss, peel pitting, and fruit decay index rate of the coated oranges. Although the bilayer PSGG/Sh coating reduced weight loss and respiration rate with improved firmness retention to a greater extent than single layer PSGG coating, the bilayer coating also resulted in higher levels of ethanol causing increased perception of off-flavors. The sensory evaluation of the oranges showed that the fruit coated with PSGG with the incorporation of Sh and single layer PSGG coatings maintained overall flavor throughout shelf life with the panellists giving higher acceptance of freshness and flavor of the coated fruit. These results suggest that PSGG-based edible coatings could be a beneficial substitute to common commercial waxes for maintaining quality and extending shelf life of citrus fruit and potentially other fresh horticultural produce. Further research on the development of new formulations by addition of bioactive compounds to PSGG-based coating and the application of this coating on microbial growth and on the physiological processes of various climacteric/non-climacteric fruit and vegetables is of great interest.

\section{Acknowledgement}



technical assistance on this project.

\section{Conflict of Interest}

The authors declare no conflict of interest.

\section{References}

Alférez, F., Burns, J.K., 2004. Postharvest peel pitting at non-chilling temperatures in grapefruit is promoted by changes from low to high relative humidity during storage. Postharvest Biol. Technol. 32, 79-87.

Arnon, H., Granit, R., Porat, R., Poverenov, E., 2015. Development of polysaccharides-based edible coatings for citrus fruits: A layer-by-layer approach. Food Chem. 166, 465-472.

529 Baldwin, E., Hagenmaier, R., Bai, J., 2011. Edible Coating and Films to improve Food Quality, 2nd ed. CRC Press, Tailor \& Francis Group FL, USA.

Baldwin, E.A., 1994. Edible coatings for fresh fruits and vegetables, past, present and future, In: Krochta, J.M., Baldwin, E.A., Nisperos-Carriedo, M.O. (Eds.), Edible Coatings and Films to Improve Food Quality. Technomic Publishing Co., Lancaster, pp. 25-64.

Baldwin, E.A., Nisperos-Carriedo, M., Shaw, P.E., Burns, J.K., 1995. Effect of coatings and prolonged storage conditions on fresh orange flavor volatiles, degrees Brix, and ascorbic acid levels. J. Agric. Food Chem. 43, 1321-1331.

Cháfer, M., Sánchez- González, L., González- Martínez, C., Chiralt, A., 2012. Fungal decay and shelf life of oranges coated with chitosan and bergamot, thyme, and tea tree essential oils. J. Food Sci. 77, E182-E187.

Cisneros- Zevallos, L., Krochta, J.M., 2002. Internal modified atmospheres of coated fresh fruits and vegetables: Understanding relative humidity effects. J. Food Sci. 67, 1990-1995. Contreras- Oliva, A., Rojas- Argudo, C., Pérez- Gago, M.B., 2012. Effect of solid content and composition of hydroxypropyl methylcellulose-lipid edible coatings on physico- chemical and nutritional quality of 'Oronules' mandarins. J. Sci. Food Agric. 92, 794-802.

Cronjé, P.J., Zacarías, L., Alférez, F., 2017. Susceptibility to postharvest peel pitting in Citrus fruits as related to albedo thickness, water loss and phospholipase activity. Postharvest Biol. Technol. 123, 77-82.

Del-Valle, V., Hernández-Muñoz, P., Guarda, A., Galotto, M., 2005. Development of a cactusmucilage edible coating (Opuntia ficus indica) and its application to extend strawberry (Fragaria ananassa) shelf-life. Food Chem. 91, 751-756. Dhall, R., 2013. Advances in edible coatings for fresh fruits and vegetables: a review. Crit. Rev. Food Sci. Nutr. 53, 435-450.

García, M.A., Martino, M.N., Zaritzky, N.E., 1999. Edible starch films and coatings characterization: scanning electron microscopy, water vapor, and gas permeabilities. Scanning 21, 348-353. 
Golding, J.B., Blades, B.L., Satyan, S., Spohr, L.J., Harris, A., Jessup, A.J., Archer, J.R., Davies, J.B., Banos, C., 2015. Low dose gamma irradiation does not affect the quality or total ascorbic acid concentration of "Sweetheart" passionfruit (Passiflora edulis). Foods 4, 376-390. Hagenmaier, R.D., 2002. The flavor of mandarin hybrids with different coatings. Postharvest Biol. Technol. 24, 79-87. Hoover, R., Sosulski, F.W., 1991. Composition, structure, functionality, and chemical modification of legume starches: a review. Can. J. Physiol. Pharmacol. 69, 79-92. Huque, R., Wills, R.B.H., Pristijono, P., Golding, J.B., 2013. Effect of nitric oxide (NO) and associated control treatments on the metabolism of fresh-cut apple slices in relation to development of surface browning. Postharvest Biol. Technol. 78, 16-23.

Koch, K., Ensikat, H.-J., 2008. The hydrophobic coatings of plant surfaces: epicuticular wax crystals and their morphologies, crystallinity and molecular self-assembly. Micron 39, 759772 .

Kumar, M., McGlasson, W., Holford, P., Golding, J., 2014. Effects of very high carbon dioxide treatment and cold storage on the quality of Navel oranges, XXIX International Horticultural Congress on Horticulture: Sustaining Lives, Livelihoods and Landscapes (IHC2014): 1120, pp. 91-98.

Liu, Q., 2005. Understanding Starches and Their Role in Foods, In: Cui, S.W. (Ed.), Food Carbohydrates: Chemistry, Physical properties, and Applications. CRC Press, Taylor \& Francis Group, Boca Raton, FL, pp. 309-356.

576 Mahfoudhi, N., Hamdi, S., 2015. Use of almond gum and gum arabic as novel edible coating to delay postharvest ripening and to maintain sweet cherry (Prunus avium) quality during storage. J. Food Process. Preserv. 39, 1499-1508. Martínez-Jávega, J.M., Cuquerella, J., del Río, M.A., Navarro, P., 1989. Coating treatments in post-harvest behavior of oranges, Technical Innovations of Freezing and Refrigeration of Fruit and Vegetables. University of California Publication, Davis, pp. 51-55.

Navarro-Tarazaga, M.L., Del Río, M.A., Krochta, J.M., Pérez-Gago, M.B., 2008. Fatty acid effect on hydroxypropyl methylcellulose-beeswax edible flm properties and postharvest quality of coated 'Ortanique' mandarins. J. Agric. Food Chem. 56, 10689-10696.

Obenland, D., Collin, S., Sievert, J., Fjeld, K., Doctor, J., Arpaia, M.L., 2008. Commercial packing and storage of navel oranges alters aroma volatiles and reduces flavor quality. Postharvest Biol. Technol. 47, 159-167.

Park, H.J., 1999. Development of advanced edible coatings for fruits. Trends Food Sci. Technol. 10, 254-260.

Petracek, P.D., Dou, H., Pao, S., 1998. The influence of applied waxes on postharvest physiological behavior and pitting of grapefruit. Postharvest Biol. Technol. 14, 99-106.

Porat, R., Weiss, B., Cohen, L., Daus, A., Biton, A., 2005. Effects of polyethylene wax content and composition on taste, quality, and emission of off-flavor volatiles in 'Mor'mandarins. Postharvest Biol. Technol. 38, 262-268.

Poverenov, E., Danino, S., Horev, B., Granit, R., Vinokur, Y., Rodov, V., 2014. Layer-by-layer electrostatic deposition of edible coating on fresh cut melon model: anticipated and unexpected effects of alginate-chitosan combination. Food Bioprocess Tech. 7, 1424-1432.

Prajapat, A.L., Gogate, P.R., 2015. Intensification of depolymerization of aqueous guar gum using hydrodynamic cavitation. Chemical Engineering and Processing: Process Intensification 93, 1-9.

Pristijono, P., Papoutsis, K., Scarlett, C.J., Bowyer, M.C., Vuong, Q.V., Stathopoulos, C.E., Golding, J.B., 2017a. Postharvest UV-C treatment combined with 1-methylcyclopropene (1MCP), followed by storage in continuous low-level ethylene atmosphere, improves the quality of tomatoes. J. Hortic. Sci. Biotechnol., 1-9. 
Pristijono, P., Scarlett, C.J., Bowyer, M.C., Vuong, Q.V., Stathopoulos, C.E., Jessup, A.J., Golding, J.B., 2017b. Use of low-pressure storage to improve the quality of tomatoes. J. Hortic. Sci. Biotechnol., 1-8.

Robles-Sánchez, R.M., Rojas-Graü, M.A., Odriozola-Serrano, I., González-Aguilar, G., Martin-Belloso, O., 2013. Influence of alginate-based edible coating as carrier of antibrowning agents on bioactive compounds and antioxidant activity in fresh-cut Kent mangoes. LWT-Food Sci. Technol. 50, 240-246.

Rodríguez, M., Oses, J., Ziani, K., Mate, J.I., 2006. Combined effect of plasticizers and surfactants on the physical properties of starch based edible films. Food Res. Int. 39, 840-846. Rojas-Argudo, C., Del Río, M., Pérez-Gago, M., 2009. Development and optimization of locust bean gum (LBG)-based edible coatings for postharvest storage of 'Fortune'mandarins. Postharvest Biol. Technol. 52, 227-234.

Saberi, B., Chockchaisawasdee, S., Golding, J.B., Scarlett, C.J., Stathopoulos, C.E., 2017. Development of biocomposite films incorporated with different amounts of shellac, emulsifier, and surfactant. Food Hydrocolloid. 72, 174-184.

Saberi, B., Thakur, R., Bhuyan, D.J., Vuong, Q.V., Chockchaisawasdee, S., Golding, J.B., Scarlett, C.J., Stathopoulos, C.E., 2016a. Development of edible blend films with good mechanical and barrier properties from pea starch and guar gum. Starch - Stärke 69, n/a-n/a.

Saberi, B., Thakur, R., Vuong, Q.V., Chockchaisawasdee, S., Golding, J.B., Scarlett, C.J., Stathopoulos, C.E., 2016b. Optimization of physical and optical properties of biodegradable edible films based on pea starch and guar gum. Ind. Crops Prod. 86, 342-352.

Saberi, B., Vuong, Q.V., Chockchaisawasdee, S., Golding, J.B., Scarlett, C.J., Stathopoulos, C.E., 2016c. Mechanical and physical properties of pea starch edible films in the presence of glycerol. J. Food Process. Preserv. 40, 1339-1351.

Tanada-Palmu, P.S., Grosso, C.R., 2005. Effect of edible wheat gluten-based films and coatings on refrigerated strawberry (Fragaria ananassa) quality. Postharvest Biol. Technol. 36, 199-208.

Tietel, Z., Lewinsohn, E., Fallik, E., Porat, R., 2011. Elucidating the roles of ethanol fermentation metabolism in causing off-flavors in mandarins. J. Agric. Food Chem. 59, 1177911785 .

Ummarat, N., Arpaia, M.L., Obenland, D., 2015. Physiological, biochemical and sensory characterization of the response to waxing and storage of two mandarin varieties differing in postharvest ethanol accumulation. Postharvest Biol. Technol. 109, 82-96.

Valencia-Chamorro, S.A., Pérez-Gago, M.B., del Río, M.Á., Palou, L., 2009. Effect of antifungal hydroxypropyl methylcellulose (HPMC)-lipid edible composite coatings on postharvest decay development and quality attributes of cold-stored 'Valencia'oranges. Postharvest Biol. Technol. 54, 72-79.

Valencia- Chamorro, S.A., Pérez- Gago, M.B., Del Río, M.A., Palou, L., 2010. Effect of antifungal hydroxypropyl methylcellulose- lipid edible composite coatings on Penicillium decay development and postharvest quality of cold- stored "Ortanique" mandarins. J. Food Sci. 75, S418-S426.

Van Soest, J.J.G., Lewin, D., Dumont, H., Kappen, F.H.J., 2002. Pea: An interesting crop for packaging applications, In: Renard, D., Della Valle, G., Popineau, Y. (Eds.), Plant Biopolymer Science: Food and Non-Food Application. The Royal Society of Chemistry, Cambridge, U.K., pp. 267-274.

Wang, J., You, Y., Chen, W., Xu, Q., Wang, J., Liu, Y., Song, L., Wu, J., 2015. Optimal hypobaric treatment delays ripening of honey peach fruit via increasing endogenous energy status and enhancing antioxidant defence systems during storage. Postharvest Biol. Technol. $101,1-9$. 
654

655

656

657

658

659

660

661

662

663

664

665

666

667

668

669

670

671

672

673

674
Whistler, R.L., BeMiller, J.N., 1993. Industrial Gums, 3rd ed. Academic Press, New York, USA.

Wills, R.B.H., Golding, J.B., 2016. Postharvest: An Introduction to the Physiology and Handling of Fruit and Vegetables. NewSouth Publishing, Sydney Australia.

659

60


676 Fig. 1. Weight loss of 'Valencia' oranges stored at different storage conditions for four weeks

677 as affected by various coatings treatments. Each bar represents the means of four replicates of 6788 fruit each $(n=32) \pm$ standard error. The different lowercase superscript letters in the same 679 storage time indicate significant differences within different coating treatments according to Duncan's test $(P<0.05)$. The different uppercase superscript letters in the same coating treatment indicate significant differences within different storage time according to Duncan's test $(P<0.05)$.

Fig. 2. Firmness of 'Valencia' oranges stored at different storage conditions for four weeks as affected by various coatings treatments. Each bar represents the means of four replicates of 8 fruit each $(n=32) \pm$ standard error. The different lowercase superscript letters in the same storage time indicate significant differences within different coating treatments according to Duncan's test $(P<0.05)$. The different uppercase superscript letters in the same coating treatment indicate significant differences within different storage time according to Duncan's test $(P<0.05)$.

Fig. 3. Respiration rate of 'Valencia' oranges stored at different storage conditions for four weeks as affected by various coatings treatments. Each bar represents the means of four replicates of 8 fruit each $(n=32) \pm$ standard error. The different lowercase superscript letters in the same storage time indicate significant differences within different coating treatments according to Duncan's test $(P<0.05)$. The different uppercase superscript letters in the same coating treatment indicate significant differences within different storage time according to Duncan's test $(P<0.05)$. 
replicates of 8 fruit each $(n=32) \pm$ standard error. The different lowercase superscript letters in the same storage time indicate significant differences within different coating treatments according to Duncan's test $(P<0.05)$. The different uppercase superscript letters in the same coating treatment indicate significant differences within different storage time according to Duncan's test $(P<0.05)$.

Fig. 5. Ethanol concentration in the juice of 'Valencia' oranges stored at different storage conditions for four weeks as affected by various coatings treatments. Each bar represents the means of four replicates of 8 fruit each $(n=32) \pm$ standard error. The different lowercase superscript letters in the same storage time indicate significant differences within different coating treatments according to Duncan's test $(P<0.05)$. The different uppercase superscript letters in the same coating treatment indicate significant differences within different storage time according to Duncan's test $(P<0.05)$.

Fig. 6. Acetaldehyde concentration in the juice of 'Valencia' oranges stored at different storage conditions for four weeks as affected by various coatings treatments. Each bar represents the means of four replicates of 8 fruit each $(n=32) \pm$ standard error. The different lowercase superscript letters in the same storage time indicate significant differences within different coating treatments according to Duncan's test $(P<0.05)$. The different uppercase superscript letters in the same coating treatment indicate significant differences within different storage time according to Duncan's test $(P<0.05)$.

Fig. 7. Peel pitting index (PPI) and percentage of fruit decay rate index (DRI) of coated and uncoated 'Valencia' oranges stored at different storage conditions for four weeks as affected by various coatings treatments. Each point is total value for $n=32$ fruit per treatment at each storage time. 
722 Fig. 8. The percentage of stem-end rind breakdown (SERB) and overall visual acceptability 723 (OVA) of coated and uncoated 'Valencia' oranges stored at different storage conditions for

724 four weeks as affected by various coatings treatments. Each point is total value for $\mathrm{n}=32$ fruit

725 per treatment at each storage time.

726 Fig. 9. Sensory evaluation of 'Valencia' oranges stored at $5{ }^{\circ} \mathrm{C}$ for four weeks plus one week 727 at $20{ }^{\circ} \mathrm{C}$ as affected by various coatings treatments. (A): Overall flavor, (B): Off-flavor, and 728 (C): Freshness. The values represent means of twelve replicates \pm standard error. The different 729 lowercase superscript letters in the same storage time indicate significant differences within 730 different coating treatments according to Duncan's test $(P<0.05)$. The different uppercase 731 superscript letters in the same coating treatment indicate significant differences within different 732 storage time according to Duncan's test $(P<0.05)$. Overall flavor was rated on a 9-point 733 hedonic scale (1=“dislike extremely", 9="like extremely"). Off-flavor and freshness were 734 assessed based on an unstructured $10 \mathrm{~cm}$ scale, with the anchor points 'none' and 'very strong' 735 for off-flavor, and 'not fresh at all' and 'very fresh' for freshness. 